\title{
Vasodilator treatment for acute and chronic heart failure
}

\author{
KANU CHATTERJEE AND WILLIAM W. PARMLEY \\ From the Department of Medicine, Cardiovascular Division, and the Cardiovascular Research Institute, \\ University of California, San Francisco, California, U.S.A.
}

The current status of the use of vasodilator drugs in the treatment of acute and chronic heart failure has been reviezved. It is apparent that vasodilator treatment can be used effectively in some patients with heart failure with a beneficial haemodynamic response, and that vasodilator agents are likely to find an important place in the management of such patients. Vasodilator treatment may be associated with complications and must be used with care. Though several nonparenteral vasodilator agents have been investigated, no ideal drug is yet available for the treatment of chronic heart failure. Nevertheless, it is probable that suitable drugs will emerge and find an important place in the management of such patients.

It has been shown that vasodilator therapy can improve cardiac performance in patients with heart failure, both acute and chronic. The ability of vasodilator drugs to increase cardiac performance is not related to a direct effect on the heart, since most of these agents have been shown to have no direct positive inotropic effects on the myocardium (Chatterjee et al., 1973a). The two primary effects of these agents appear to be on the postcapillary capacitance bed and on the precapillary resistance bed. Vasodilator agents increase the venous capacitance, causing an increase in the relative size of the venous blood pool, a decrease in intracardiac blood volume (preload), and a decrease in systemic and pulmonary venous pressures. The other major effect of these drugs is to decrease arteriolar resistance and thus unload the heart; this unloading of the heart seems to be the most important mechanism whereby these drugs improve cardiac performance. It has been established in the isolated heart muscle preparation that with constant initial muscle length (preload), the degree of shortening is inversely proportional to afterload (Sonnenblick, 1962). This suggests that in the intact heart reduction in the afterload would result in enhanced myocardial fibre shortening and stroke

'This work was supported in part by a Program Project Grant from the U.S. Public Health Service.

Received for publication 19 July 1976 volume. In relation to isolated muscle mechanics, the term afterload has been used to refer to the additional load above the preload, against which the muscle works as it shortens. To relate this concept to the intact heart, it is strictly necessary to measure wall stress during ejection, which according to the Laplace equation depends upon intraventricular pressure, wall thickness, and ventricular size and shape. This would be particularly difficult to determine during the ejection phase because of the rapidly changing relation between all these variables. A more practical and simple method of defining the load resisting ejection in the intact heart is to consider the systolic impedance. Though a precise definition of impedance involves consideration of a series of harmonics which describe pressure and flow (Milnor, 1975), an approximation can be derived from the analysis of the instantaneous relation between pressure and flow during ejection (impedance $=P / Q$, where $P$ and $\dot{Q}$ are instantaneous pressure and flow, respectively). Thus, a reduction in ejection impedance can be produced by a reduction in systolic pressure and/or an increase in stroke output. It is clear that ejection impedance is closely related to peripheral vascular resistance. Thus, though the vasodilator drugs which reduce peripheral vascular resistance are often referred to as 'afterload reducing agents', it is preferable to describe their effect in terms of im- 


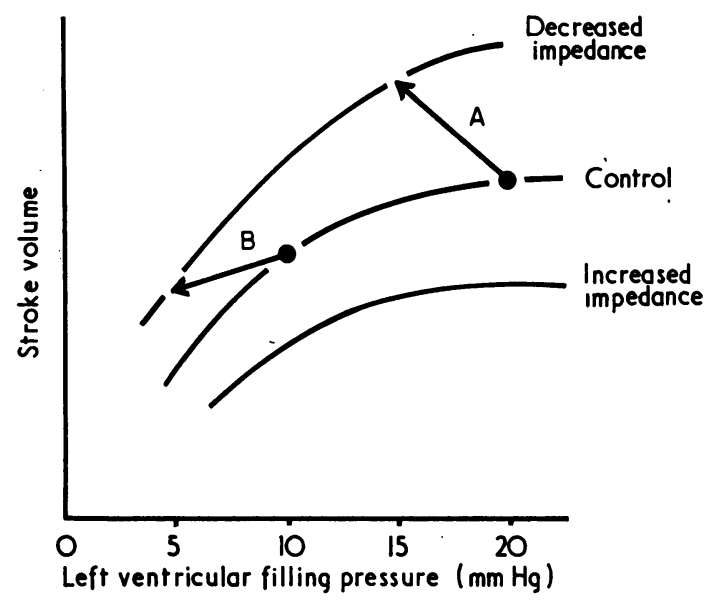

Fig. 1 Diagrammatic illustration of the effects of changes in impedance and preload on the ventricular function curve. The control ventricular function curve shows an increase in left ventricular stroke volume with an increase in left ventricular filling pressure up to an optimal level of 15 to $20 \mathrm{mmHg}$. Vasodilator drugs, which decrease impedance, shift this curve upwards while vasopressor drugs, which increase impedance, shift the curve downwards. Line $A$ shows a beneficial response to vasodilator therapy when the filling pressure is relatively high: the reduction in left ventricular filling pressure is accompanied by an increase in stroke volume. Line $B$ shows a decrease in stroke volume during vasodilator therapy when initial filling pressure is low: though the reduction of impedance tends to increase stroke volume, this is offset by the further reduction in filling pressure down the ascending limb of the ventricular function curve; the net effect is a reduction in stroke volume.

pedance reduction. Though the precise quantification of impedance is difficult, the concept is extremely valuable, and in many ways it is better to consider impedance than arterial pressure alone. For example, some patients who receive vasodilators show an increase in stroke volume and cardiac output without any change in arterial pressure. In this situation, there is an unloading of the ventricle in terms of impedance reduction, despite the lack of a fall in arterial pressure.

Although most vasodilator agents produce similar haemodynamic effects, the haemodynamic response may vary. Thus, most vasodilators have dilating effects on both the resistance and the capacitance vascular beds. However, the arteriolar resistance bed may be predominantly affected by some vasodilator drugs and the venous capacitance beds by others; other vasodilator agents possess balanced effects on these two vascular beds. The quantitative difference in the haemodynamic response to different vasodilator agents is not only related to their different pharmacological properties, but also to the types of patients being treated. Vasodilator agents may cause an increase, a decrease, or no change in left ventricular stroke volume and cardiac output, depending on the level of initial left ventricular filling pressure (Fig. 1). As a result of the curvilinear relation between left ventricular stroke volume and filling pressure, decreased aortic impedance in the patient represented by the line $\mathrm{A}$ is associated with an increase in stroke volume, despite a substantial decrease in left ventricular filling pressure. In contrast, in a patient with initially low left ventricular filling pressure (B), a further decrease in left ventricular filling pressure associated with a decrease in aortic impedance of similar magnitude may result in a decrease in stroke volume. Furthermore, in patients with high filling pressure, there is usually no change or a slight reduction in heart rate. In patients with a low initial filling pressure, there is often a compensatory tachycardia in an attempt to maintain cardiac output. This emphasises the importance of determining left ventricular filling pressure before vasodilator treatment is started, if the objective of treatment is to improve cardiac performance.

For the treatment of pump failure, acute or chronic, several vasodilator agents have been used with beneficial haemodynamic effects. Some of the vasodilator drugs are used intravenously, while some can be administered by other routes. In the following section, the role of vasodilator treatment in the management of pump failure, complicating acute myocardial infarction or chronic refractory heart failure, will be discussed. An attempt will be made to assess the advantages and disadvantages of the various vasodilator agents in relation to the specific objective of treatment.

\section{Vasodilator treatment for heart failure in acute myocardial infarction}

The haemodynamic effects of various vasodilator agents, including sodium nitroprusside (Franciosa et al., 1972; Chatterjee et al., 1973a; Chatterjee and Swan, 1973, 1974), phentolamine (Kelly et al., 1973; Walinsky et al., 1974; Gould et al., 1974; Perret et al., 1975), nitroglycerin, both intravenous and sublingual (Flaherty et al., 1975; Come et al., 1975; Borer et al., 1975; Armstrong et al., 1975a; Gold et al., 1972; Williams et al., 1975a), trimetaphan (Shell and Sobel, 1974), and isosorbide dinitrate (Mantle et al., 1976), have been investigated in patients with acute myocardial infarction.

The haemodynamic effects of sodium nitro- 


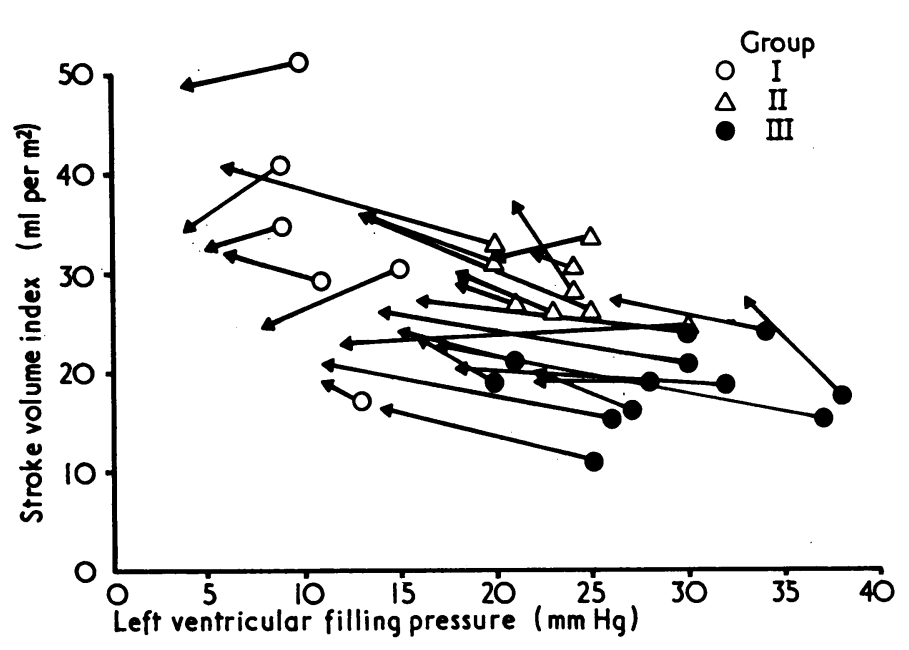

Fig. 2 Changes in left ventricular filling pressure and stroke volume during nitroprusside infusion in a group of patients with acute myocardial infarction. Group I represents patients with an initial left ventricular filling pressure less than $15 \mathrm{mmHg}$. The patients in group II had clinically moderate left ventricular failure, with initial left ventricular filling pressure and stroke work index higher than

$15 \mathrm{mmHg}$ and $20 \mathrm{~g} \mathrm{~m}$ per $\mathrm{m}^{2}$, respectively. While group III patients had severe left ventricular failure, with a left ventricular filling pressure higher than $15 \mathrm{mmHg}$ and stroke work index of $20 \mathrm{~g} \mathrm{~m} \mathrm{per} \mathrm{m}^{2}$ or less. In group II and III patients, nitroprusside infusion produced a reduction in filling pressure along with an increase in stroke volume. In group I patients with an initially low filling pressure, stroke volume usually decreased with a further reduction in filling pressure (Chatterjee and Parmley, 1976 : reprinted by permission of Progress in Cardiovascular Diseases).

prusside infusion in 27 patients with acute myocardial infarction are summarised in Table 1. Patients were divided into three groups on the basis of the initial left ventricular filling pressure (pulmonary artery wedge or pulmonary artery end diastolic pressure) and stroke work index. Group I included those patients with filling pressure (LVFP) less than $15 \mathrm{mmHg}$, the majority of patients being free from clinical signs and symptoms of left ventricular failure. The patients in group II had initial left ventricular filling pressures higher than $15 \mathrm{mmHg}$ and a stroke work index greater than $20 \mathrm{~g} \mathrm{~m}$ per m $\mathrm{m}^{2}$ BSA; the majority of the patients in this group had frank pulmonary oedema and all had clinical and radiological evidence of left ventricular failure. Group III patients included those with LVFP greater than $15 \mathrm{mmHg}$ and stroke work index of $20 \mathrm{~g} \mathrm{~m}$ per $\mathrm{m}^{2}$ or less; all patients in this group had clinically severe left ventricular failure and frank pulmonary oedema; furthermore, the majority of patients in this group were hypotensive and several patients had clinical features of shock. The usual haemodynamic response to nitroprusside infusion in each group was a decrease in systemic and pulmonary vascular resistance, a decrease in pulmonary arterial, right atrial, and left ventricular

Table 1 Haemodynamic effects of nitroprusside infusion in patients with acute myocardial infarction $\dagger$

\begin{tabular}{|c|c|c|c|c|c|c|}
\hline \multirow[t]{2}{*}{ No. of patients } & \multicolumn{2}{|l|}{$\begin{array}{l}\text { Group I } \\
6\end{array}$} & \multicolumn{2}{|l|}{$\underset{9}{\text { Group II }}$} & \multicolumn{2}{|l|}{$\begin{array}{l}\text { Group } I I I \\
12\end{array}$} \\
\hline & $C$ & $N P$ & $C$ & $N P$ & $C$ & $N P$ \\
\hline $\begin{array}{l}\text { Heart rate (beats/min) } \\
\text { Mean arterial pressure (mmHg) } \\
\text { Mean pulmonary arterial pressure } \\
\text { (mmHg) }\end{array}$ & $\begin{array}{l}89 \cdot 0 \pm 7 \cdot 1 \\
91 \cdot 0 \pm 2 \cdot 6 \\
16 \cdot 5 \pm 1 \cdot 7\end{array}$ & $\begin{array}{l}96 \cdot 7 \pm 8 \cdot 6 \\
85 \cdot 8 \pm 3 \cdot 9 \\
11 \cdot 3 \pm 1 \cdot 0 \star\end{array}$ & $\begin{array}{r}91 \cdot 3 \pm 4 \cdot 2 \\
100 \cdot 6 \pm 4 \cdot 5 \\
31 \cdot 8 \pm 1 \cdot 6\end{array}$ & $\begin{array}{l}94 \cdot 7 \pm 3 \cdot 4 \\
87 \cdot 7 \pm 4 \cdot 1 \\
23 \cdot 9 \pm 2 \cdot 0 \star\end{array}$ & $\begin{array}{r}100 \cdot 2 \pm 4 \cdot 0 \\
82 \cdot 4 \pm 2 \cdot 2 \\
37 \cdot 0 \pm 1 \cdot 5\end{array}$ & $\begin{aligned} 100 \cdot 5 & \pm 4 \cdot 8 \\
76 \cdot 2 & \pm 2 \cdot 8 \star \\
24 \cdot 7 & \pm 1 \cdot 4\end{aligned}$ \\
\hline $\begin{array}{l}\text { Mean right atrial pressure (mmHg) } \\
\text { Left ventricular filling pressure } \\
\text { (mmHg) }\end{array}$ & $\begin{array}{r}5 \cdot 2 \pm 1 \cdot 4 \\
11 \cdot 2 \pm 4 \cdot 6\end{array}$ & $\begin{array}{l}2 \cdot 8 \pm 1 \cdot 2 \\
6 \cdot 3 \pm 1 \cdot 1^{\star}\end{array}$ & $\begin{array}{l}10 \cdot 4 \pm 1 \cdot 5 \\
23 \cdot 6 \pm 1 \cdot 0\end{array}$ & $\begin{aligned} 7 \cdot 2 & \pm 1 \cdot 4^{\star} \\
15 \cdot 2 & \pm 1 \cdot 5^{\star}\end{aligned}$ & $\begin{array}{l}12 \cdot 8 \pm 1 \cdot 4 \\
29 \cdot 0 \pm 1 \cdot 6\end{array}$ & $\begin{aligned} 8 \cdot 5 & \pm 1 \cdot 3 \star \\
18 \cdot 7 & \pm 1 \cdot 8^{\star}\end{aligned}$ \\
\hline $\begin{array}{l}\text { Cardiac index }\left(1 / \mathrm{min} \text { per } \mathrm{m}^{2}\right) \\
\text { Stroke work index }\left(\mathrm{g} \mathrm{m} \text { per } \mathrm{m}^{2}\right) \\
\text { Systemic vascular resistance } \\
\left.\text { (dynes } 8 \mathrm{~cm}^{-5}\right)\end{array}$ & $\begin{aligned} 2 \cdot 9 & \pm 0 \cdot 2 \\
38 \cdot 8 & \pm 7 \cdot 6 \\
1383 & \pm 148\end{aligned}$ & $\begin{array}{r}2 \cdot 9 \pm 0 \cdot 2 \\
34 \cdot 5 \pm 6 \cdot 2 \\
1321 \pm 119\end{array}$ & $\begin{aligned} 2 \cdot 6 & \pm 0 \cdot 1 \\
33 \cdot 6 & \pm 2 \cdot 9 \\
1577 & \pm 141\end{aligned}$ & $\begin{aligned} 3 \cdot 1 & \pm 0 \cdot 2 \star \\
34 \cdot 2 & \pm 1 \cdot 8 \\
1231 & \pm 146\end{aligned}$ & $\begin{aligned} 1 \cdot 8 & \pm 0 \cdot 1 \\
13 \cdot 8 & \pm 1 \cdot 1 \\
1908 & \pm 260\end{aligned}$ & $\begin{aligned} 2 \cdot 2 & \pm 0 \cdot 1^{\star} \\
17 \cdot 6 & \pm 1 \cdot 5^{\star} \\
1431 & \pm 137^{\star}\end{aligned}$ \\
\hline
\end{tabular}

All results expressed as mean $\pm S E M$.

$C$, control; NP, during nitroprusside therapy.

$\star \mathbf{P}<0.05$ (nitroprusside $\mathrm{v}$ control).

+Chatterjee et al. (1973a). 
filling pressures, together with a slight to moderate decrease in mean arterial pressure. Cardiac index and stroke volume index, however, increased consistently only in group II and group III patients. Despite a fall in arterial pressure, stroke work index increased in most patients in these two groups. Heart rate also did not change in these patients. In contrast, in patients without left ventricular failure and with normal left ventricular filling pressure (group I), cardiac index did not change and stroke volume and stroke work indices declined, with a reflex increase in heart rate. An increase in stroke volume with a decrease in left ventricular filling pressure, suggesting improved left ventricular performance, was seen in patients in groups II and III, but not in group I (Fig. 2). Decreases in systemic vascular resistance and in systemic and pulmonary venous pressures, in patients receiving nitroprusside infusion, suggest that nitroprusside possesses dilating effects on both precapillary resistance and postcapillary capacitance vascular beds. Miller et al. (1975) have suggested that nitroprusside has a relatively balanced effect on these two vascular beds. Absence of an increase in stroke volume in patients with initially normal left ventricular filling pressure is probably related to a move down the ascending limb of the ventricular function curve with a further reduction in enddiastolic volume. Cardiac output and stroke volume may not increase in some patients with high left ventricular filling pressure if this is reduced considerably to a very low level. These observations emphasise the importance of monitoring left ventricular filling pressure, not only to identify those patients likely to derive haemodynamic benefits from nitroprusside infusion, but also to avoid excessive reduction of left ventricular filling pressure.
The haemodynamic effects of intravenous phentolamine in patients with acute myocardial infarction are similar to those of sodium nitroprusside (Kelly et al., 1973; Walinsky et al., 1974; Gould et al., 1974; Perret et al., 1975). Phentolamine, an $\alpha$-adrenergic blocking agent, also possesses direct smooth muscle relaxing effects. It not only reduces arteriolar tone, but also increases peripheral venous capacitance (Abboud et al., 1968). Phentolamine decreases systemic and pulmonary vascular resistances, and arterial, pulmonary arterial, and left ventricular filling pressures. Right atrial pressure also falls in the majority of patients. In most patients (approximately 90\%) with raised left ventricular filling pressure, cardiac output and stroke volume increase. In patients with normal left ventricular filling pressure, however, changes in cardiac output and stroke volume are less consistent. Thus, improved left ventricular performance with phentolamine tends to occur, as with nitroprusside, in patients with high left ventricular filling pressure. One significant difference between the haemodynamic effects of sodium nitroprusside and those of intravenous phentolamine is the tendency to develop tachycardia during phentolamine infusion. In approximately 80 per cent of patients with acute myocardial infarction with either normal or raised left ventricular filling pressures, significant tachycardia occurs during phentolamine infusion (Fig. 3). The mechanism responsible for tachycardia with phentolamine is not clear. Increased synthesis and release of cardiac noradrenaline has been shown to occur in experimental animals (Dairman et al., 1968; Bagwell et al., 1970) and might possibly play a role in phentolamine-induced tachycardia. Phentolamine has also been shown to have indirect inotropic effects in experimental animals (Singh et al., 1970; Zahir and Gould, 1971). From a

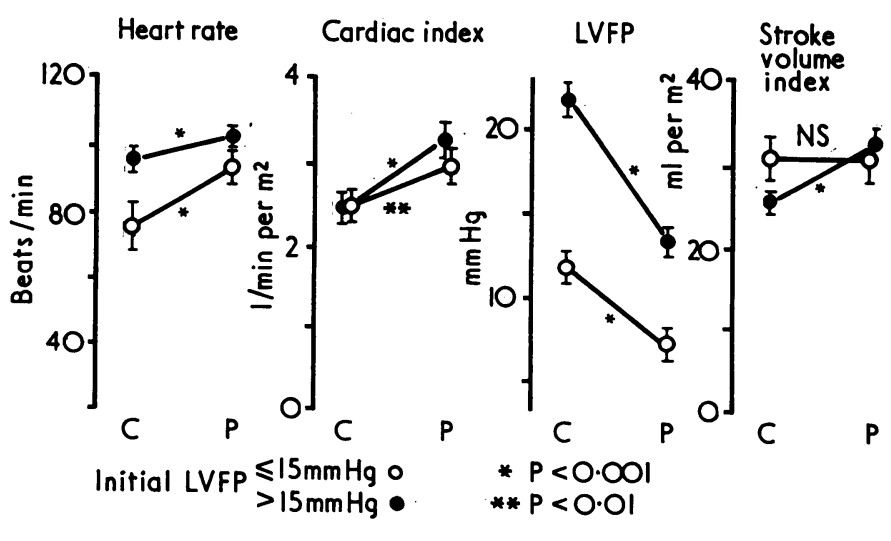

Fig. 3 The haemodynamic effects of phentolamine in patients with acute myocardial infarction are summarised from the published reports (Kelly et al., 1973; Walinsky et al., 1974; Gould et al., 1974; Perret et al., 1975). Patients were divided into two groups: those with initial left ventricular filling pressure less than $15 \mathrm{mmHg}$ (O) (14 patients), and those with initial left ventricular filling pressure greater than $15 \mathrm{mmHg}$ (O) (37 patients). Stroke volume increased consistently only in patients with higher left ventricular filling pressure. Heart rate, however, increased in both groups (Chatterjee and Parmley, 1976 : reprinted by permission of Progress in Cardiovascular Diseases). $C=$ control $; P=$ after phentolamine. 
practical point of view, tachycardia and indirect inotropic effects during.phentolamine therapy are distinct disadvantages, because of the possible increase in myocardial oxygen demand which might jeopardise ischaemic myocardium in these patients.

Nitroglycerin, whether administered intravenously or sublingually, and sublingual isosorbide dinitrate, cause a significant decrease in left ventricular filling pressure and right atrial pressure as a result of their dilating effect on the capacitance venous bed. Arteriolar dilatation with nitrites is less and so the decrease in systemic vascular resistance and left ventricular ejection impedance tend to be less than the reduction in preload. Therefore, though there is almost always a decrease in left ventricular filling pressure, there is little or no increase and may even be a decrease in cardiac output and stroke volume. The changes in stroke volume and in left ventricular filling pressure produced by nitroglycerin in patients with acute myocardial infarction (both sublingual and intravenous) are shown in Fig. 4; These haemodynamic data have been collected from published reports (Gold et al., 1972; Williams et al., 1975a; Flaherty et al., 1975; Come et al., 1975; Borer et al., 1975; Armstrong et al., 1975b). It is apparent that there was usually a decrease in stroke volume in patients with a normal left ventricular filling pressure, and when the filling pressure decreased to significantly less than $15 \mathrm{mmHg}$ after nitroglycerin. When left ventricular filling pressure remained above $15 \mathrm{mmHg}$, stroke volume either remained unchanged or increased, though the magnitude of the increase in stroke volume was usually unimpressive. Heart rate tends to increase when there is a decrease in stroke volume resulting from a pronounced decrease in left ventricular filling pressure.

The haemodynamic effects of these vasodilator agents may provide a rational basis for the choice of a particular agent for a specific therapeutic objective. If the major purpose of treatment is to relieve pulmonary venous congestion in patients who have a persistently raised left ventricular filling pressure, with relatively adequate cardiac output at rest, nitrites might fulfil this objective. On the other hand, if inadequate cardiac output accompanies high left ventricular filling pressure, nitroprusside or phentolamine might be the agents of choice. However, much more clinical experience will be needed to confirm the validity of such a therapeutic approach to the management of pump failure complicating acute myocardial infarction.

\section{Metabolic response to vasodilator treatment} in patients with acute myocardial infarction

A potential hazard of vasodilator therapy in patients with obstructive coronary artery disease, with or without recent myocardial infarction, is increased myocardial ischaemia as a result of a reduction in arterial pressure and therefore coronary artery perfusion pressure. Myocardial perfusion however, is dependent not only on the perfusion pressure but also on the resistance of the distal coronary artery bed and transmyocardial pressure gradient (Fortuin et al., 1971). Furthermore, concomitant changes in the determinants of myocardial oxygen requirement will influence myocardial ischaemia by changing the ratio of oxygen supply to demand. Myocardial metabolism during vaso-

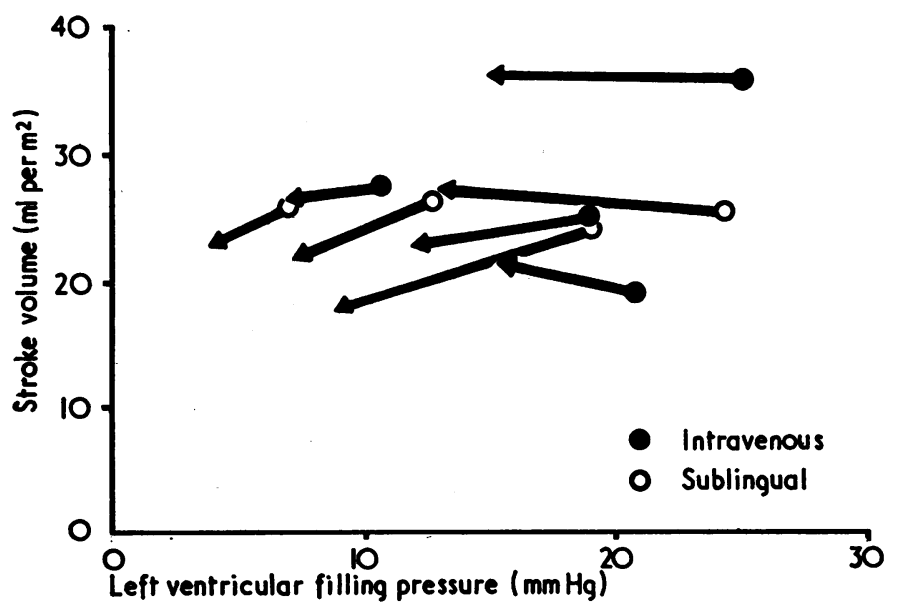

Fig. 4 Haemodynamic effects of intravenous (45 patients) and sublingual nitroglycerin (28 patients) in acute myocardial infarction. Data collected from published report; (Flaherty et al., 1975; Come et al., 1975; Borer et al., 1975; Armstrong et al., 1975a, b; Williams et al., 1975b). Patients were divided into those with high initial filling pressure (more than $15 \mathrm{mmHg}$ ) and those with low initial filling pressure, and the former were further subdivided into those in whom filling pressure fell significantly and those in whom it did not. It is apparent that the predominant effect of nitroglycerin was to reduce left ventricular filling pressure, though stroke volume increased slightly in some patients with initially high filling pressure. 
dilator therapy will depend on these various opposing factors which might alter both myocardial perfusion and the determinants of myocardial oxygen demand.

In experimental animals with patent coronary arteries, sodium nitroprusside decreases coronary vascular resistance and increases coronary blood flow (Rowe and Henderson, 1974). But in patients with acute myocardial infarction complicated by left ventricular failure, coronary sinus blood flow, an approximate measure of coronary blood flow, myocardial oxygen extraction, and consumption all tend to decrease during vasodilator treatment (Chatterjee et al., 1973a). This is consistent with the fact that the major determinants of myocardial oxygen demand either remain unchanged or fall: left ventricular systolic and end diastolic pressures decrease, while heart rate and myocardial contractility are unaffected. There was no change in myocardial lactate extraction during vasodilator therapy, indicating that there was no increase in myocardial ischaemia in these patients.

Intravenous phentolamine increases overall myocardial blood flow in patients with acute myocardial infarction, despite a fall in blood pressure (Gould et al., 1975). However, this increase in coronary blood flow may be partly the result of an increase in myocardial oxygen demand, as a result of tachycardia.

Although the metabolic effects of nitroglycerin have been investigated in patients with chronic ischaemic heart disease (Brachfeld et al., 1959; Gorlin et al., 1959; Frohlich and Scott, 1962; Luebs et al., 1966; Ganz and Marcus, 1972), little is known about changes in myocardial metabolism after nitroglycerin in patients with acute myocardial infarction. When there is left ventricular failure, nitroglycerin, like nitroprusside, decreases left ventricular systolic and end diastolic pressures without any significant change in heart rate or contractility. It is likely, therefore, that overall myocardial oxygen demand and blood flow would decrease in such patients during nitroglycerin treatment. Thus, the overall myocardial oxygen supply/demand ratio and myocardial metabolism might improve. But an excessive reduction in arterial pressure, irrespective of the vasodilator used, might, by reducing coronary blood flow, aggravate myocardial hypoxia. Furthermore, even with a moderate reduction in arterial pressure, there is a possibility of increased hypoxia in some areas of the myocardium as a result of the reduction in perfusion pressure during vasodilator treatment. It would be useful to be able to measure regional metabolism, to determine the degree of reduction of arterial pressure that could be tolerated, but in clinical practice this is not possible at the present time.
In experimental models, investigations of changes in regional metabolism of ischaemic myocardial segments during vasodilator treatment have produced conflicting results. Some authors have reported improvement in regional myocardial metabolism and mechanical function during nitroprusside infusion (Cohn et al., 1974a; Mueller et al., 1974; Da Luz et al., 1975; Ramanathan et al., 1975) and others deterioration or no change (Kerber and Abboud, 1975; Kerber et al., 1976; Chiariello et al., 1976). Similarly, there have been contradictory and conflicting reports on the effects of nitroglycerin on the extent of myocardial ischaemic injury, as judged by changes in the magnitude of ST segment elevation after acute myocardial infarction. Decrease in ST segment elevation suggesting reduction of the extent of myocardial ischaemic injury has been observed during nitroglycerin therapy (Borer et al., 1975; Come et al., 1975; Flaherty et al., 1975; Chiariello et al., 1976). However, no change or even an increase in ST segment elevation has been reported by Lang $e t$ al. (1976). Furthermore, a paradoxical adverse effect of nitroglycerin on segmental left ventricular wall motion has also been reported in patients with obstructive coronary artery disease and 'coronary steal' has been suggested as the underlying mechanism (Codini et al., 1976). Fam and McGregor (1964) have previously suggested that a 'coronary steal syndrome' might occur with nitroglycerin where there is a large proximal resistance within diseased coronary arteries. This 'coronary steal' from ischaemic myocardium may also occur with nitroprusside or phentolamine and result in increased ischaemia (Chiariello et al., 1976; Brown et al., 1976; Farnham et al., 1976; Engler et al., 1976).

These limited experimental and clinical investigations suggest that, irrespective of the vasodilator agent used, the effects of vasodilator treatment on the metabolic and mechanical function of ischaemic myocardium are likely to be variable, being determined by concurrent changes in the various factors that influence myocardial perfusion and oxygen demand. Furthermore, extrapolation of the results of experimental studies to the treatment of patients is difficult and should be done with extreme caution. Not only is coronary anatomy different in experimental animals, but the experimental design may be far removed from actual clinical situations. For example, the effects of vasodilators on regional myocardial metabolism and on the extent of myocardial ischaemic injury have been studied in experimental animals within a few minutes of acute coronary artery occlusion, whereas most patients with acute myocardial infarction are 
treated several hours or days after the onset. In addition, most experimental studies have been performed in animals without heart failure, while vasodilator treatment is most useful haemodynamically in patients with significant pump failure. Thus, the effects of vasodilator treatment on relatively ischaemic or hypoxic myocardial segments in patients with obstructive coronary artery disease remain uncertain. But it should be emphasised that in clinical practice a large reduction in arterial pressure, particularly in hypotensive or normotensive patients, whichever vasodilator agent is used, should be avoided since this may aggravate existing myocardial ischaemia. Fortunately, when the objective of treatment is to improve pump function, the beneficial haemodynamic effects of vasodilator treatment can be obtained in many patients without a significant reduction in arterial pressure (Chatterjee et al., 1973a).

\section{Influence of vasodilator treatment on prognosis of pump failure complicating acute myocardial infarction}

In recent years, as hospital mortality from primary arrhythmias has strikingly decreased, pump failure has emerged as the primary cause of death in patients with acute myocardial infarction. It has also become apparent that the mortality from pump failure is directly proportional to the severity of depression of cardiac function. Thus, the hospital mortality with conventional therapy is 30 to 40 per cent in patients with frank pulmonary oedema, and approaches 100 per cent when the clinical features of cardiogenic shock are present (Killip and Kimball, 1967; Swan et al., 1970; Wolk et al., 1972; Scheidt et al., 1973; Weber et al., 1973). With the advent of safe bedside monitoring, prognostic indices based on haemodynamic data have become available. Whether overt clinical manifestations of pump failure are present or not, certain haemody-
Table 2 Clinical data in 43 patients with severe pump failure complicating acute myocardial infarction treated with intravenous vasodilators $\star$

\begin{tabular}{lc}
\hline Clinical data & No. of patients \\
\hline Site of infarct & \\
Anterior & 26 \\
Inferior & 10 \\
Combined & 3 \\
Posterior & 1 \\
Subendocardial & 1 \\
Left bundle-branch block & 2 \\
Previous infarct & 30 \\
Cardiomegaly & 31 \\
Pulmonary oedema & 43 \\
Shock & 17 \\
Complications of treatment & \\
Sudden hypotension & 3 \\
Nausea & 4 \\
Mental confusion & 3 \\
Hiccough & 9 \\
\hline
\end{tabular}

*Chatterjee et al., 1976c.

namic measurements provide a sensitive means of evaluating the immediate prognosis of such patients. In patients with a stroke work index of $20 \mathrm{~g} \mathrm{~m}$ per $\mathrm{m}^{2}$ or less and a left ventricular filling pressure of $15 \mathrm{mmHg}$ or more, the hospital mortality with conventional therapy approaches 80 per cent (Chatterjee and Swan, 1973). Whether such a grim outlook in these patients is influenced favourably by vasodilator treatment cannot be determined with certainty without a matched control series. However, recent investigations suggest that intravenous vasodilator treatment with careful haemodynamic monitoring might improve the immediate prognosis in patients with severe pump failure complicating acute myocardial infarction (Chatterjee et al., 1976c). Forty-three patients with severe pump failure were treated with nitroprusside (40 patients) or phentolamine (3 patients); clinical data including complications of vasodilator therapy are summarised in Table 2 . Not only clinically, but also on the basis of initial haemodynamic observations

Table 3 Haemodynamic changes during intravenous vasodilator therapy in 43 patients with severe pump failure complicating acute myocardial infarction *

\begin{tabular}{|c|c|c|c|}
\hline & Control & Vasodilator & $\boldsymbol{P}$ \\
\hline $\begin{array}{l}\text { Heart rate (beats/min) } \\
\text { Arterial mean pressure (mmHg) } \\
\text { Pulmonary arterial mean pressure }(\mathrm{mmHg}) \\
\text { Right atrial mean pressure }(\mathrm{mmHg}) \\
\text { Left ventricular filling pressure }(\mathrm{mmHg}) \\
\text { Cardiac index }\left(1 / \mathrm{min} \text { per } \mathrm{m}^{2}\right) \\
\text { Stroke volume index }\left(\mathrm{ml} \mathrm{per} \mathrm{m}^{2}\right) \\
\text { Stroke work index }\left(\mathrm{g} \mathrm{per} \mathrm{m}^{2}\right) \\
\text { Systemic vascular resistance }\left(\text { dynes } \mathrm{s} \mathrm{cm}^{-5}\right)\end{array}$ & $\begin{aligned} 100 & \pm 2 \cdot 4 \\
83 & \pm 1 \cdot 5 \\
39 & \pm 1 \cdot 2 \\
13 & \pm 0 \cdot 8 \\
31 & \pm 1 \cdot 0 \\
1 \cdot 7 & \pm 0 \cdot 05 \\
17 \cdot 3 & \pm 0 \cdot 2 \\
14 & \pm 0 \cdot 7 \\
2023 & \pm 112\end{aligned}$ & $\begin{aligned} 99 & \pm 2 \cdot 7 \\
73 & \pm 1 \cdot 7 \\
28 & \pm 1 \cdot 1 \\
9 & \pm 0 \cdot 6 \\
20 & \pm 0 \cdot 8 \\
2 \cdot 2 & \pm 0 \cdot 06 \\
22 \cdot 8 & \pm 0 \cdot 8 \\
19 & \pm 0 \cdot 9 \\
1435 & \pm 65\end{aligned}$ & $\begin{array}{l}\text { NS } \\
<0.0005 \\
<0.0005 \\
<0.0005 \\
<0.0005 \\
<0.0005 \\
<0.0005 \\
<0.005 \\
<0.0005\end{array}$ \\
\hline
\end{tabular}

All results expressed as mean \pm SEM.

Chatteriee et al. (1976c). 


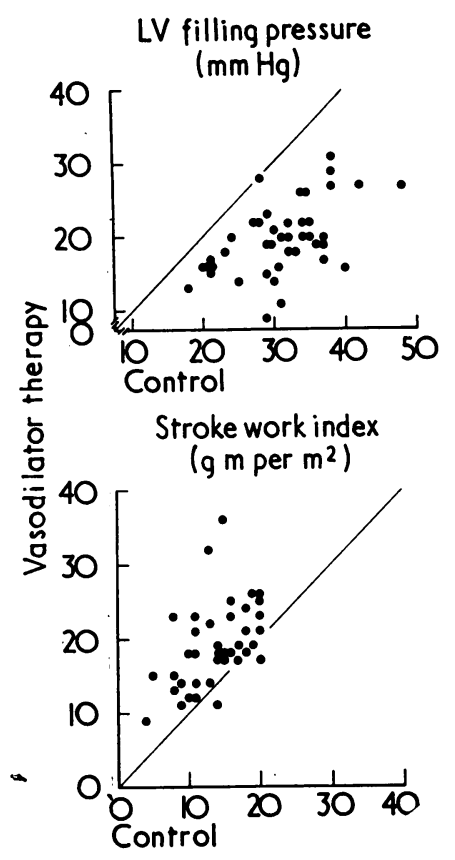

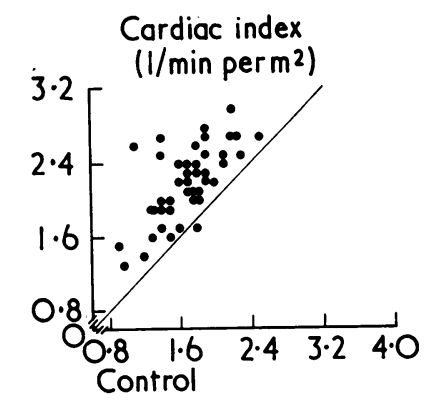

Systemic vascular resistance (dynes $5 \mathrm{~cm}^{-5}$ )

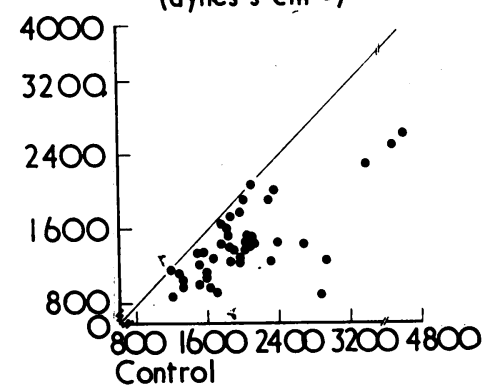

Fig. 5 Changes in left ventricular filling pressure, cardiac index, stroke work index, and systemic vascular resistance during intravenous vasodilator treatment in 43 patients with severe pump failure complicating acute myocardial infarction. In almost all patients haemodynamic improvement was observed (Chatterjee et al., 1976c: reprinted by permission of Circulation). (stroke work index less than $20 \mathrm{~g} \mathrm{~m}$ per $\mathrm{m}^{2}$ and left ventricular filling pressure more than $15 \mathrm{mmHg}$ ), these patients had severe depression of cardiac function. Haemodynamic changes during intravenous vasodilator treatment are summarised in Table 3. A beneficial haemodynamic response was observed in almost all patients. Cardiac output increased while pulmonary artery wedge pressure decreased (Fig. 5). Despite this initial favourable haemodynamic response, 19 patients $(44 \%)$ died in the hospital, 15 with uncontrolled failure. Thus, hospital mortality caused by pump failure was 34 per cent. Most studies indicate that in the presence of severe haemodynamic depression, the hospital mortality with conventional treatment exceeds 75 per cent. With vasodilator treatment in patients with similar haemodynamic findings, mortality was about 50 per cent (Table 4). However, when the stroke work index is extremely low (less than $10 \mathrm{~g} \mathrm{~m}$ per $\mathrm{m}^{2}$ ) and left ventricular filling pressure is raised, the immediate prognosis remains very bad. Eleven of the 43 patients had a stroke work index less than $10 \mathrm{~g} \mathrm{~m}$ per $\mathrm{m}^{2}$; of these only 2 survived, giving a hospital mortality of 82 per cent. Thus, it appears that vasodilator treatment is most likely to be effective in patients with an initial stroke work index greater than $10 \mathrm{~g} \mathrm{~m}$ per $\mathrm{m}^{2}$ and raised left ventricular filling pressure.

Although these findings suggest an improvement in the initial prognosis of patients with severe pump failure using vasodilator treatment, the late prognosis was unfavourable in the survivors. Sixty-two per cent of the survivors died within 1 to 25 months (average 9.2 months) after discharge, and 71 per cent

Table 4 Comparison of mortality rates with conventional and vasodilator treatment in power failure after acute myocardial infarction

\begin{tabular}{|c|c|c|c|c|c|c|c|c|}
\hline \multirow[t]{2}{*}{ Authors } & \multirow{2}{*}{$\begin{array}{l}\text { No. of } \\
\text { patients }\end{array}$} & \multirow{2}{*}{$\begin{array}{l}C I \\
\left(l / m i n \text { per } m^{2}\right)\end{array}$} & \multirow{2}{*}{$\begin{array}{l}S W I \\
\left(g m \text { per } m^{2}\right)\end{array}$} & \multirow{2}{*}{$\begin{array}{l}L V F P \\
(m m H g)\end{array}$} & \multirow{2}{*}{$\begin{array}{l}C W I \\
\left(k g m \text { per } m^{2}\right)\end{array}$} & \multirow[t]{2}{*}{$S W I / L V F P$} & \multicolumn{2}{|c|}{ Per cent mortality } \\
\hline & & & & & & & Conventional & Vasodilator \\
\hline Ratshin et al. (1972) & 11 & $2 \cdot 3$ & - & 15 & - & - & 100 & 53 \\
\hline Scheidt et al. (1973) & 29 & - & 20 & - & - & - & 72 & 44 \\
\hline Scheidt et al. (1973) & 29 & 一 & - & - & $1 \cdot 75$ & - & 76 & 50 \\
\hline Bleifeld et al. (1974) & 42 & - & - & - & - & $1 \cdot 2$ & 80 & 44 \\
\hline Chatterjee et al. (1973a, 1976c) & 15 & - & 20 & 15 & 一 & - & 80 & 44 \\
\hline
\end{tabular}

CI, cardiac index; SWI, stroke work index; LVFP, left ventricular filling pressure; CWI, cardiac work index. 
Control

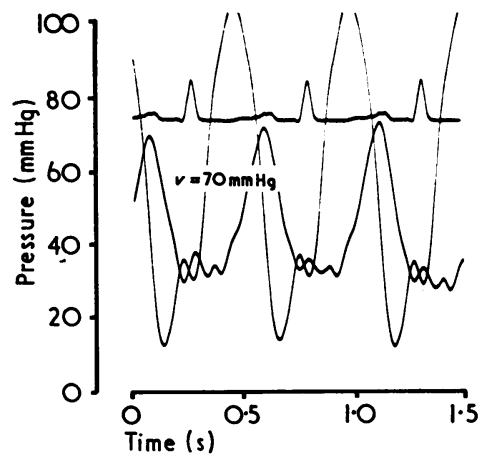

Nitroprusside

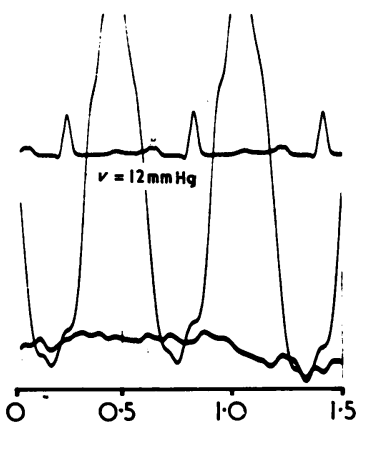

Fig. 6 Simultaneously recorded left ventricular pressure and pulmonary artery wedge pressure before and 25 minutes later during nitroprusside infusion in a patient with severe mitral regurgitation. $A$ distinct decrease in pulmonary artery wedge mean pressure, the height of the $\mathrm{v}$ wave, and in left ventricular end diastolic pressure was seen during nitroprusside infusion (Chatterjee et al., $1973 \mathrm{~b}$ : reprinted by permission of Circulation). died of uncontrolled pump failure. Furthermore, about 50 per cent of the survivors remained in severe pump failure. It is apparent that the longterm prognosis in these patients remains bad.

\section{Vasodilator treatment for valvular regurgitation}

\section{MITRAL REGURGITATION}

As an increase in impedance to left ventricular ejection increases mitral regurgitation (Braunwald et al., 1957), it is not surprising that vasodilator agents can produce beneficial haemodynamic effects in patients with mitral regurgitation (Chatterjee et al., 1973b; Goodman et al., 1974; Sniderman et al., 1974; Harshaw et al., 1975). The haemodynamic effects of intravenous sodium nitroprusside infusion are a decrease in systemic and pulmonary vascular resistance, and a decrease in pulmonary artery wedge, right atrial, and pulmonary artery pressures. Left ventricular forward stroke volume and cardiac output increases and usually there is no significant change in heart rate (Table 5). Reduction in the regurgitant volume during nitroprusside infusion is indicated by a distinct decrease in the amplitude of the peak $v$ wave in the pulmonary artery wedge pressure (Fig. 6). Indeed, the calculated regurgitant volume decreases considerably during nitroprusside infusion, with a concomitant increase in forward stroke volume and little change in the total stroke volume (Fig. 7). This redistribution of the total stroke volume of the left ventricle, with more blood ejected forwards into the aorta and less backwards into the left atrium, accounts for the distinct haemodynamic improvement in these patients. Since the left ventricle operates at a lower filling pressure and end diastolic volume, the calculated ejection fraction usually increases. The decrease in the regurgitant volume, however, may not be entirely the result of the reduction of impedance to left ventricular ejection. Decreased left ventricular chamber size and improved functional integrity of the mitral valve apparatus may play a significant role.

Intravenous phentolamine and nitroglycerin (sublingual or topical) produce haemodynamic effects that are very similar to those of nitroprusside. With nitroglycerin, however, forward stroke volume

Table 5 Haemodynamic effects of nitroprusside in 8 patients with mitral regurgitation *

\begin{tabular}{|c|c|c|c|}
\hline & Control & Nitroprusside & $P$ \\
\hline $\begin{array}{l}\text { Heart rate (beats/min) } \\
\text { Arterial mean pressure }(\mathrm{mmHg}) \\
\text { Pulmonary arterial mean pressure }\left(\mathrm{mmHg}^{\mathrm{m}}\right) \\
\text { Pulmonary artery mean wedge pressure }(\mathrm{mmHg}) \\
\text { Pulmonary artery wedge pressure } v \text { wave }(\mathrm{mmHg}) \\
\text { Cardiac index }\left(1 / \text { min per } \mathrm{m}^{2}\right) \\
\text { Forward stroke volume index }\left(\mathrm{ml} \text { per } \mathrm{m}^{2}\right) \\
\text { Stroke work index }\left(\mathrm{g} \text { mer } \mathrm{m}^{2}\right) \\
\text { Systemic vascular resistance }\left(\text { dynes s } \mathrm{cm}^{-5}\right) \\
\text { Pulmonary vascular resistance }\left(\text { dynes } \mathrm{cm}^{-5}\right)\end{array}$ & $\begin{aligned} 101 & \pm 5 \cdot 9 \\
83 & \pm 3 \cdot 8 \\
45 & \pm 2 \cdot 4 \\
33 & \pm 1 \cdot 8 \\
50 & \pm 4 \cdot 5 \\
2 \cdot 2 & \pm 0 \cdot 35 \\
23 & \pm 4 \cdot 4 \\
16 & \pm 3 \\
1802 & \pm 331 \\
263 & \pm 45\end{aligned}$ & $\begin{aligned} 95 & \pm 4 \cdot 9 \\
70 & \pm 3 \cdot 3 \\
29 & \pm 2 \cdot 4 \\
16 & \pm 1 \cdot 4 \\
19 & \pm 2 \cdot 9 \\
3 \cdot 3 & \pm 0 \cdot 47 \\
36 & \pm 6 \cdot 6 \\
29 & \pm 6 \\
1102 & \pm 241 \\
163 & \pm 26\end{aligned}$ & $\begin{array}{l}<0.01 \\
<0.005 \\
<0.0005 \\
<0.0005 \\
<0.0005 \\
<0.005 \\
<0.005 \\
<0.01 \\
<0.005 \\
<0.025\end{array}$ \\
\hline
\end{tabular}

All results expressed as mean \pm SEM.

*Chatterjee et al. (1973b). 

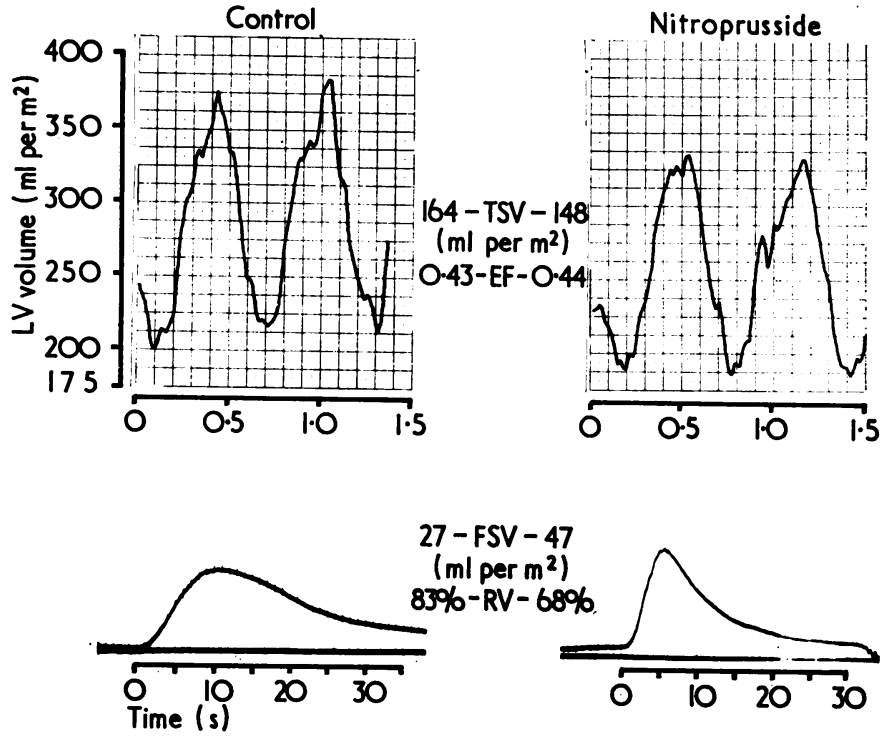

Fig. 7 Changes in the regurgitant volume during nitroprusside infusion in a patient with severe mitral regurgitation. Regurgitant volume ( $R V)$ was calculated by subtracting the forward stroke volume (FSV) obtained from the dye concentration curves (lower panels) from the total left ventricular stroke volume (TSV) calculated from the left ventricular volume curves (upper panels) obtained from left ventriculograms in right anterior oblique projection, and was expressed as a percentage of the total stroke volume. $R V$ decreased significantly during nitroprusside infusion. Ejection fraction (EF) is unchanged. (Chatterjee et al., $1973 b$ : reprinted by permission of Circulation). may not increase, in spite of a decrease in regurgitant volume. This may result from the striking reduction in end diastolic volume, related to the greater effect of nitroglycerin on ventricular preload than on afterload.

\section{AORTIC REGURGITATION}

It has been recognised clinically for a long time that inhalation of amyl nitrite, a vasodilator, decreases the duration and intensity of the AustinFlint murmur in patients with aortic regurgitation, indicating a reduction in regurgitant volume. Indeed, the administration of amyl nitrite results in a decrease in arterial pressure and left ventricular end diastolic pressure, together with an increase in effective stroke volume (Delius and Enghoff, 1970). Similar beneficial haemodynamic effects of sodium nitroprusside are seen particularly in those patients with a raised left ventricular end diastolic pressure and reduced ejection fraction. Determination of instantaneous changes in pressure and flow in the aortic root during nitroprusside infusion show that there is a significant reduction in aortic impedance which might account for the increase in forward stroke volume and reduction of regurgitant fraction in patients with aortic regurgitation (Pepine et al., 1976; Bolen and Alderman, 1976). There is usually, however, a slight to moderate decrease in arterial pressure. Therefore, in patients with aortic regurgitation and associated obstructive coronary artery disease, vasodilators should be used cautiously, because a further reduction of an already reduced aortic diastolic pressure may impair myocardial perfusion.
Since vasodilator treatment may improve the haemodynamic state of patients with mitral or aortic regurgitation, it can be applied with advantage in certain clinical situations. In patients with acute mitral regurgitation complicating myocardial infarction, it may be possible to defer a hazardous surgical operation (Fig. 8). Similarly, when acute aortic regurgitation with cardiac failure complicates bacterial endocarditis, there is a potential role for vasodilator treatment to tide the patients over a critical period until the infection is under control. When surgical treatment is contraindicated in patients with chronic mitral or aortic regurgitation, the addition of vasodilators to conventional antifailure treatment may produce significant haemodynamic and clinical improvement. It is also possible that the smaller left ventricular volume, reduced regurgitant fraction, and decreased left ventricular work that results from vasodilator treatment may be helpful in delaying the progressive ventricular dysfunction that occurs in patients with severe mitral or aortic regurgitation. Without further experience, however, the efficacy of vasodilator treatment for long-term management of patients with valvar regurgitation remains conjectural.

\section{Vasodilator treatment for chronic congestive heart failure}

Congestive heart failure, irrespective of the aetiology, not uncommonly becomes refractory to conventional therapy with digitalis and diuretics. The haemodynamic effects of intravenous sodium 


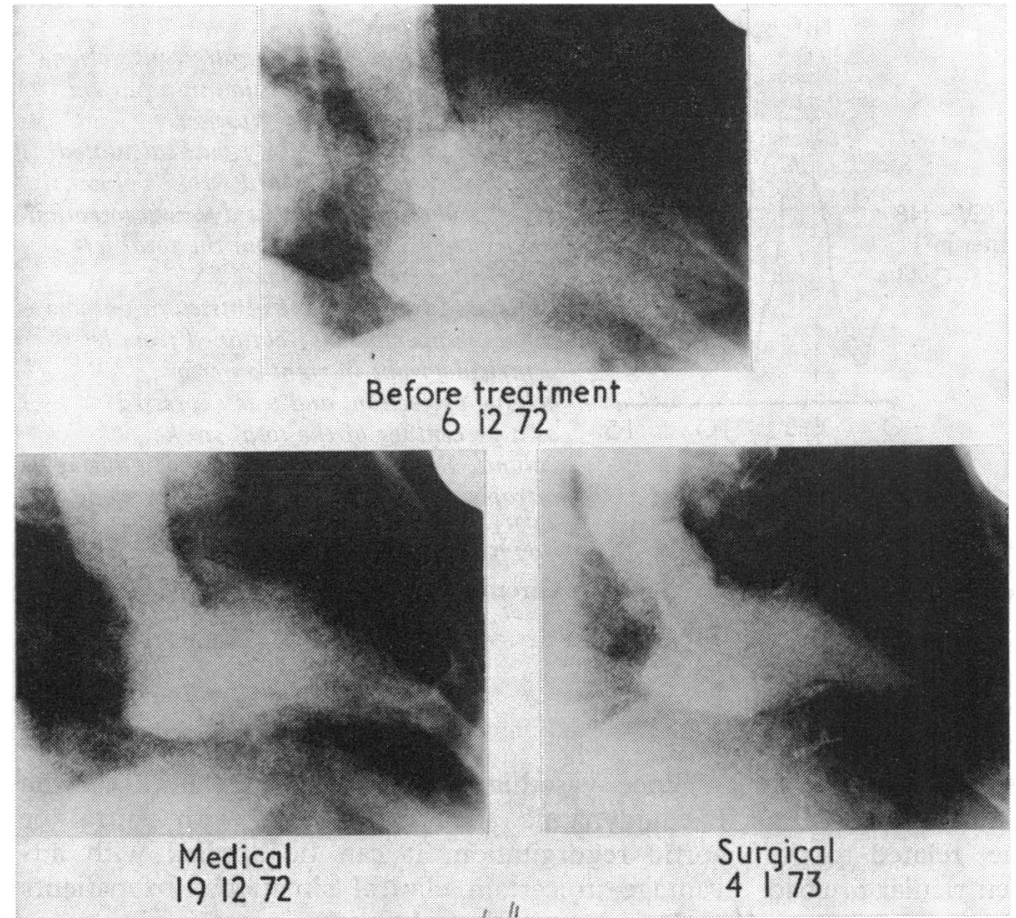

Fig. 8 End systolic frames from left ventriculograms in right anterior oblique projection in a patient with severe mitral regurgitation as a reuslt of papillary muscle dysfunction complicating acute myocardial infarction. Before vasodilator treatment, important mitral regurgitation was shown by dense opacification of the left atrium during left ventriculograms (6.12.72). During vasodilator treatment left ventriculograms showed an obvious reduction in severity of mitral regurgitation 19.12.72). The patient was maintained on vasodilator treatment until operation was performed. The postoperative study (4.1.73) showed no significant mitral regurgitation. nitroprusside in patients with chronic congestive heart failure are similar to those observed in patients with acute heart failure (Cohn et al., 1974b; Guiha et al., 1974; Chatterjee, 1975; Miller et al., 1975; Chatterjee et al., 1976a; Chatterjee and Parmley, 1976). With an adequate dose, cardiac output and stroke volume increase, with decreases in systemic vascular resistance, and in mean arterial and pulmonary artery pressures. Peripheral venous capacitance also increases with a decrease in right atrial and pulmonary artery wedge pressures (Fig. 9). This favourable haemodynamic response is usually accompanied by clinical improvement. Intravenous phentolamine produces similar haemodynamic effects (Gould et al., 1969; Majid et al., 1971; Williams et al., 1975b). These haemodynamic effects of nitroprusside or phentolamine are quickly reversed when intravenous treatment is discontinued. Intravenous treatment is thus clinically applicable only for the short-term management of patients with chronic congestive heart failure or to determine the magnitude of the haemodynamic response before starting nonparenteral vasodilator treatment.

Several nonparenteral vasodilators have been investigated for the long-term management of heart failure. Sublingual nitroglycerin (Gold et al., 1972) usually decreases pulmonary and systemic venous pressures. Cardiac output may or may not increase. Clinically, therefore, sublingual nitroglycerin can be used effectively for the treatment of acute pulmonary oedema. The duration of action of sublingual nitroglycerin is extremely short, not exceeding 30 minutes; thus its clinical use in the long-term management of heart failure is limited.

The haemodynamic effects of nitroglycerin ointment, which are similar to those of the sublingual form, last approximately 3 to 5 hours (Taylor et al., 1975). Though there is usually a significant reduction in systemic and pulmonary venous pressures, the increase in cardiac output is usually only slight. In some patients with severe heart failure there may be no haemodynamic changes (Chatterjee et al., 1976a), perhaps because of lack of absorption. Furthermore, the effective dose for an individual patient cannot be predicted without haemodynamic measurements.

Sublingual isosorbide dinitrate, in a dose of 2.5 to $15 \mathrm{mg}$, decreases systemic and pulmonary venous pressure, as a result of an increase in peripheral venous capacitance. Cardiac output increases slightly along with a decrease in arterial pressure (Gray et al., 1975). The haemodynamic and peripheral vascular effects of isosorbide dinitrate 

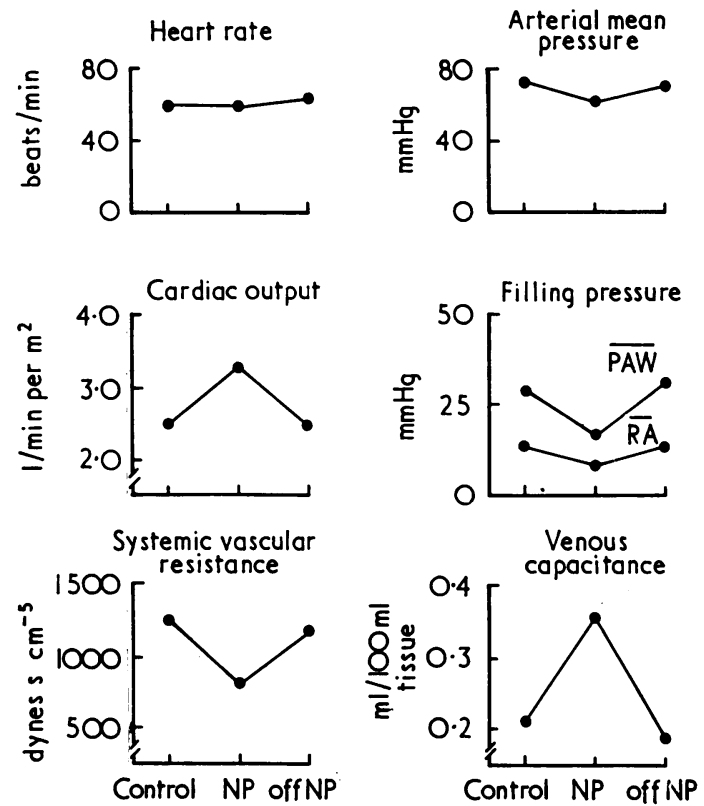

Fig. 9 Effect of intravenous nitroprusside (NP) infusion on peripheral vascular and central haemodynamic changes in a patient with severe chronic congestive heart failure. Pulmonary arterial wedge pressure and right atrial pressure decreased with an increase in venous capacitance. Cardiac output increased with a decrease in systemic vascular resistance. Mean arterial pressure decreased only slightly and the heart rate did not change. Haemodynamic values returned almost to control level after stopping nitroprusside infusion.

become evident within 15 minutes and are maximal between 15 and 45 minutes, but last for approximately 90 minutes (Fig. 10). Frequent administration is therefore necessary. Oral isosorbide dinitrate in a dose of 20 to $40 \mathrm{mg}$ may cause a significant decrease in pulmonary venous pressures for 3 to 4 hours in some patients with chronic congestive heart failure, though its effect on cardiac output is unknown (Franciosa et al., 1974). Chewable isosorbide dinitrate also appears to be effective in reducing pulmonary and systemic venous pressures (Mikulic et al., 1975). From the clinical experience reported so far, it appears that most nitrite preparations can produce a significant reduction in pulmonary and systemic venous pressures and so are useful for the relief of pulmonary and systemic venous congestion. As the increase in cardiac output is no more than slight, nitrites may be less effective in those patients with left ventricular failure in whom a low cardiac output is the primary problem. A vasodilator agent with a predominant effect on the precapillary resistance bed may produce a greater increase in cardiac output and therefore be more useful.

Preliminary experience with oral hydrallazine, a predominantly arteriolar dilator, in patients with refractory heart failure has shown that it can produce a sustained increase in cardiac output and stroke volume (Chatterjee et al., 1976b; Franciosa and Cohn, 1976), together with a significant reduction in systemic vascular resistance. When hydrallazine was administered in a dose of $\mathbf{5 0}$ to $75 \mathrm{mg}$ every 6 hours, no consistent changes in systemic and pulmonary venous pressures, arterial pressure, or heart rate were observed (Table 6). It is not clear why there was no change in heart rate in these patients: a relatively minor reduction in arterial pressure or possibly a sluggish baroreceptor response in patients with chronic heart failure might be responsible. The absence of a significant reduction in arterial pressure in normotensive patients may be an advantage of this drug in the management of patients with heart failure caused by ischaemic heart disease, since coronary artery perfusion pressure would be maintained. On the other hand, systemic and pulmonary venous pressures may remain high and weight gain resulting from an increase in extracellular and plasma volume may occur despite an increase in cardiac output during treatment with oral hydrallazine. The

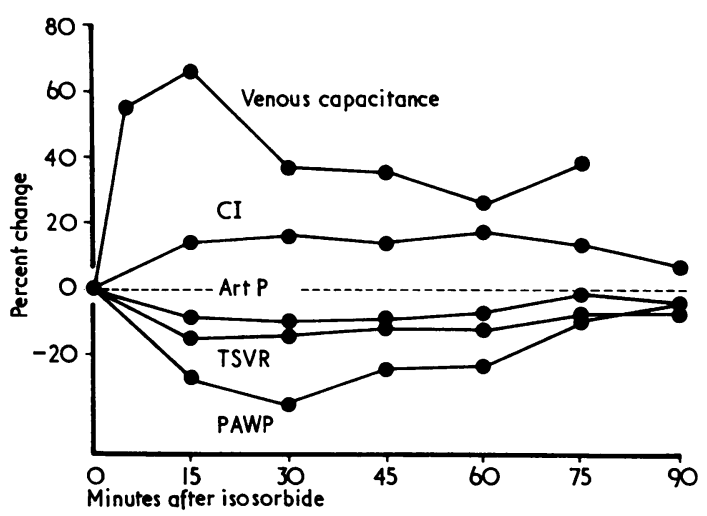

Fig. 10 Haemodynamic effects of sublingual isosorbide dinitrate in patients with chronic congestive heart failure. These data represent the mean percentage change from control values in 12 patients. There was an increase in cardiac index (CI), stroke volume, and venous capacitance, and a decrease in systemic vascular resistance (TSVR), pulmonary arterial wedge pressure $(P A W P)$, and arterial pressure (Art $P)$, lasting about 90 minutes (Gray et al., 1975 : reprinted by permission of American Heart Journal). 
Table 6 Haemodynamic effects of oral hydrallazine in 10 patients with refractory heart failure

\begin{tabular}{|c|c|c|c|}
\hline & Control & Hydrallazine & $P$ \\
\hline $\begin{array}{l}\text { Heart rate (beats/min) } \\
\text { Arterial mean pressure (mmHg) } \\
\text { Pulmonary arterial mean pressure }(\mathrm{mmHg}) \\
\text { Left ventricular filling pressure }(\mathrm{mmHg}) \\
\text { Cardiac index }\left(1 / \mathrm{min} \text { per } \mathrm{m}^{2}\right) \\
\text { Stroke volume index }\left(\mathrm{ml} \mathrm{per} \mathrm{m}^{2}\right) \\
\text { Stroke work index }\left(\mathrm{g} \mathrm{m} \text { per } \mathrm{m}^{2}\right) \\
\text { Systemic vascular resistance }(\text { dynes } \mathrm{s} \mathrm{cm}-5) \\
\text { Pulmonary vascular resistance }\left(\text { dynes } 8 \mathrm{~cm}^{-5}\right)\end{array}$ & $\begin{aligned} 90 & \pm 6 \cdot 9 \\
89 & \pm 4 \cdot 5 \\
37 & \pm 3 \cdot 4 \\
24 & \pm 2 \cdot 0 \\
1 \cdot 99 & \pm 0 \cdot 15 \\
23 & \pm 3 \cdot 0 \\
23 & \pm 2 \cdot 4 \\
1748 & \pm 129 \\
328 & \pm 54\end{aligned}$ & $\begin{aligned} 90 & \pm 5 \cdot 8 \\
85 & \pm 4 \cdot 0 \\
38 & \pm 3 \cdot 1 \\
23 & \pm 2 \cdot 1 \\
3 \cdot 39 & \pm 0 \cdot 29 \\
38 & \pm 3 \cdot 5 \\
36 & \pm 3 \cdot 7 \\
998 & \pm 115 \\
203 & \pm 32\end{aligned}$ & $\begin{array}{l}\text { NS } \\
\text { NS } \\
\text { NS } \\
\text { NS } \\
<0.001 \\
<0.001 \\
<0.001 \\
<0.001 \\
<0.001\end{array}$ \\
\hline
\end{tabular}

NS $=$ not significant.

$\star$ Chatterjee et al. (1976b).

addition of diuretics and nitrites is therefore necessary.

\section{Complications}

Unexpected hypotension is the most serious complication of intravenous vasodilator treatment and may be hazardous for patients with acute myocardial infarction and pump failure, but is usually reversed within 5 to 10 minutes after stopping intravenous treatment. To avoid hypotension sodium nitroprusside or phentolamine should be started in a very low dose (nitroprusside 16 to 20 $\mu \mathrm{g}$ per $\mathrm{min}$, phentolamine 0.1 to $0.2 \mathrm{mg}$ per $\mathrm{min}$ ); the subsequent increase in dose should also be gradual. Careful monitoring of changes in cardiac output, systemic vascular resistance, and filling pressures is necessary. The maximum dose of vasodilator needs to be determined for each individual patient. Nitroprusside has been used without adverse effects in doses up to $430 \mu \mathrm{g}$ per min, and phentolamine in doses up to $2 \mathrm{mg}$ per $\mathrm{min}$ in patients with acute heart failure. Mental confusion, involuntary muscular twitchings, convulsions, nausea, vomiting, and hiccough are other complications of intravenous vasodilator treatment. Methaemoglobinaemia, hypothyroidism, and cyanide poisoning are rare but serious potential complications of nitroprusside treatment. In patients needing prolonged nitroprusside treatment, blood thiocyanate level should be monitored, particularly in the presence of hepatic and renal failure which retard the metabolism of nitroprusside: the toxic level of thiocyanate is about $12 \mathrm{mg} / \mathrm{dl}$.

The nonparenteral vasodilators sublingual nitroglycerin and isosorbide dinitrate may produce severe unexpected hypotension. Headache, nausea, and postural hypotension are potential problems of nitrate therapy. Limited experience in patients with chronic heart failure has shown that oral hydrallazine in doses of 50 to $75 \mathrm{mg}$ every 6 hours does not produce postural hypotension. Nausea and abdominal discomfort are usually transient complications of hydrallazine treatment. Central nervous system complications, skin eruption, peripheral neuropathy, and the systemic lupus erythematosus syndrome are more serious complications of continued hydrallazine treatment; the risks increase when the daily dose exceeds $400 \mathrm{mg}$. Long-term follow-up and further experience will be needed to determine the incidence of these complications in patients with heart failure receiving hydrallazine; without this experience the feasibility of hydrallazine treatment for the long term management of heart failure remains uncertain.

\section{References}

Abboud, F. M., Schmid, P. G., and Eckstein, J. W. (1968). Vascular responses after alpha-adrenergic receptor blockade. I. Responses of capacitance and resistance vessels to norepinephrine in man. Fournal of Clinical Investigation, 47, 1-9.

Armstrong, P. W., Mathew, M. T., Boroomand, K., and Parker, J. O. (1975a). Hemodynamic effects of nitroglycerin ointment in acute myocardial infarction. Circulation, 51 and 52, Suppl. II, 152.

Armstrong, P. W., Walker, D. C., Burton, J. R., and Parker, J. O. (1975b). Vasodilator therapy in acute myocardial infarction. A comparison of sodium nitroprusside and nitroglycerin. Circulation, 52, 1118-1122.

Bagwell, E. E., Hilliard, C. C., Daniell, H. B., Taylor, P. L., and Walton, R. P. (1970). Studies on the inotropic mechanism of phentolamine. American fournal of Cardiology, 25, 83.

Bleifeld, W., Hanrath, P., Mathey, D., and Merx, W. (1974). Acute myocardial infarction. V. Left and right ventricular haemodynamics in cardiogenic shock. British Heart Fournal, 36, 822-834.

Bolen, J. L., and Alderman, E. L. (1976). Hemodynamic consequences of afterload reduction in patients with chronic aortic regurgitation. Circulation, 53, 879-883.

Borer, J. S., Redwood, D. R., Levitt, B., Cagin, N., Bianchi, C., Vallin, H., and Epstein, S. E. (1975). Reduction in myocardial ischaemia with nitroglycerin or nitroglycerin plus phenylephrine administered during acute myocardial infarction. New England fournal of Medicine, 293, 1008-1012.

Brachfeld, N., Bozer, J., and Gorlin, R. (1959). Action of nitroglycerin on the coronary circulation in normal and in mild cardiac subjects. Circulation, 19, 697-704. 
Braunwald, E., Welch, G. H., and Sarnoff, S. J. (1957). Hemodynamic effects of quantitatively varied experimental mitral regurgitation. Circulation Research, 5, 539545.

Brown, T. M., Matthews, O. P., and Walter, P. F. (1976). Assessment of the effect of vasodilator therapy upon hemodynamics and ischemic injury in acute myocardial infarction. American fournal of Cardiology, 37, 123.

Chatterjee, K. (1975). Vasodilator therapy for heart failure. Annals of Internal Medicine, 83, 421-423.

Chatterjee, K., Drew, D., Parmley, W. W., Klausner, S. C. Polansky, J., and Zacherle, B. (1976a). Combination vasodilator therapy for severe chronic congestive heart failure. Annals of Internal Medicine.

Chatterjee, K., and Parmley, W. W. (1976). The role of vasodilator therapy in heart failure. Progress in Cardiovascular Diseases, 19, 301-325.

Chatteriee, K., Parmley, W. W., Ganz, W., Forrester, J., Walinsky, P., Crexells, C., and Swan, H. J. C. (1973a). Hemodynamic and metabolic responses to vasodilator therapy in acute myocardial infarction. Circulation, 48, 1183-1193.

Chatterjee, K., Parmley, W. W., Massie, B., Greenberg, B., Werner, J., Klausner, S., and Norman, A. (1976b). Oral hydralazine therapy for chronic refractory heart failure. Circulation, 54, 879-883.

Chatterjee, K., Parmley, W. W., Swan, H. J. C., Berman, G., Forrester, J., and Marcus, H. S. (1973b). Beneficial effects of vasodilator agents in severe mitral regurgitation due to dysfunction of subvalvar apparatus. Circulation, 48, 684 690.

Chatterjee, K., and Swan, H. J. C. (1973). Hemodynamic profile in acute myocardial infarction. In Myocardial Infarction, p. 51. Ed. by E. Corday and H. J. C. Swan. Williams and Wilkins, Baltimore.

Chatterjee, K., and Swan, H. J. C. (1974). Vasodilator therapy in acute myocardial infarction. Modern Concepts of Cardiovascular Disease, 43, 119-124.

Chatterjee, K., Swan, H. J. C., Kaushik, V. S., Jobin, G. Magnusson, P., and Forrester, J. S. (1976c). Effects of vasodilator therapy for severe pump failure in acute myocardial infarction on short term and late prognosis. Circulation, 53, 797-802.

Chiariello, M., Gold, H. K., Leinbach, R. C., Davis, M. A., and Maroko, P. R. (1976). Comparison between the effects of nitroglycerin and nitroprusside on ischemic injury during acute myocardial infarction (abstract). American fournal of Cardiology, 37, 127.

Codini, M. A., Bardfeld, P. A., and Spindola-Franco, H. (1976). Paradoxical effect of nitroglycerin on left ventricular wall motion in coronary artery disease. American fournal of Cardiology, 37, 127.

Cohn, J. N., Franciosa, J. A., and Notargiacomo, A. (1974a). Nitroprusside and dobutamine effect on myocardial oxygen supply/demand in experimental myocardial infarction. Circulation, 49 and 50, Suppl. III, 103.

Cohn, J. N., Mathew, K. J., Franciosa, J. A., and Snow, J. A. (1974b). Chronic vasodilator therapy in the management of cardiogenic shock and intractable left ventricular failure. Annals of Internal Medicine, 81, 777-780.

Come, P. C., Flaherty, J. T., Baird, M. C., Rouleau, J. R., Weisfeldt, M. L., Greene, H. L., Becker, L., and Pitt, B. (1975). Reversal by phenylephrine of the beneficial effects of intravenous nitroglycerin in patients with acute myocardial infarction. New England fournal of Medicine, 293, 1003-1007.

Dairman, W., Gordon, R., Spector, S., Sjoerdsma, A., and Udenfriend, S. (1968). Effect of $a$-blockers on catecholamine biosynthesis. Federation Proceedings, 27, 240.

Da Luz, P. L., Forrester, J. S., Wyatt, H. L., Tyberg, J. V.,
Chagrasulis, R., Parmley, W. W., and Swan, H. J. C. (1975). Hemodynamic and metabolic effects of sodium nitroprusside on the performance and metabolism of regional ischemic myocardium. Circulation, 52, 400-407.

Delius, W., and Enghoff, E. (1970). Studies of the central and peripheral hemodynamic effects of amyl nitrite in patients with aortic insufficiency. Circulation, 42, 787-796.

Engler, R. L., Pearlman, A. S., Goldstein, R. A., Kent, K. M., and Epstein, S. E. (1976). Relative effects of nitroprusside and nitroglycerin on ischemia after experimental coronary occlusion. Clinical Research, 24, 216A.

Fam, W. M., and McGregor, M. (1964). Effect of coronary vasodilator drugs on retrograde flow in areas of chronic myocardial ischaemia. Circulation Research, 15, 355-365.

Farnham, D. J., Shah, P. M., Logan, D. C., and Schreiner, B. F. (1976). Nitroprusside ventriculogram: impairment of asynergy. American fournal of Cardiology, 37, 135.

Flaherty, J. T., Reid, P. R., Kelly, D. T., Taylor, D. R., Weisfeldt, M. L., and Pitt, B. (1975). Intravenous nitroglycerin in acute myocardial infarction. Circulation, 51, 132-139.

Fortuin, N. J., Kaihara, S., Becker, L. C., and Pitt, B. (1971). Regional myocardial blood flow in the dog studied with radioactive microspheres. Cardiovascular Research, 5, 331336.

Franciosa, J. A., and Cohn, J. N. (1976). Hemodynamic improvement with hydralazine in left heart failure. Clinical Research, 24, 217A.

Franciosa, J. A., Guiha, N. H., Limas, C. J. Rodriguera, E., and Cohn, J. N. (1972). Improved left ventricular function during nitroprusside infusion in acute myocardial infarction. Lancet, 1, 650-654.

Franciosa, J. A., Mikulic, E., Cohn, J. N., Jose, E., and Fabie, A. (1974). Hemodynamic effects of orally administered isosorbide dinitrate in patients with congestive heart failure. Circulation, 50, 1020-1024.

Frohlich, E. D., and Scott, J. B. (1962). The local effect of glyceryl trinitrate, nitrite, papaverine and atropine upon coronary vascular resistance. American Heart fournal, 63, 362-366.

Ganz, W., and Marcus, H. S. (1972). Failure of intracoronary nitroglycerin to alleviate pacing-induced angina. Circulation, 46, 880-889.

Gold, H. K., Leinbach, R. C., and Sanders, C. A. (1972). Use of sublingual nitroglycerin in congestive heart failure following acute myocardial infarction. Circulation, 46, 839-845.

Goodman, D. J., Rossen, R. M., Holloway, E. L., Alderman, E. L., and Harrison, D. C. (1974). Effect of nitroprusside on left ventricular dynamics in mitral regurgitation. Circulation, 50, 1025-1032.

Gorlin, R., Brachfeld, N., Macleod, C., and Bopp, P. (1959). Effect of nitroglycerin on the coronary circulation in patients with coronary artery disease or increased left ventricular work. Circulation, 19, 705-718.

Gould, L., Reddy, C. V. R., Blatt, C. J., Gomprecht, R. F., and Hayt, D. B. (1975). Effects of phentolamine on coronary blood flow in patients with recent myocardial infarction. British Heart fournal, 37, 647-651.

Gould, L., Reddy, C. V. R., Kalanithi, P., Espina, L., and Gomprecht, R. F. (1974). Use of phentolamine in acute myocardial infarction. American Heart fournal, 88, 144-148.

Gould, L., Zahir, M., and Ettinger, S. (1969). Phentolamine and cardiovascular performance. British Heart fournal, 31, 154-162.

Gray, R., Chatteriee, K., Vyden, J. K., Ganz, W., Forrester, J. S., and Swan, H. J. C. (1975). Hemodynamic and metabolic effects of isosorbide dinitrate in chronic congestive heart failure. American Heart fournal, 90, 346-352.

Guiha, N. H., Cohn, J. N., Mikulic, E., Franciosa, J., and 
Limas, C. J. (1974). Treatment of refractory heart failure with infusion of nitroprusside. New England fournal of Medicine, 291, 587-592.

Harshaw, C. W., Grossman, W., Munro, A. B., and McLaurin, L. P. (1975). Reduced systemic vascular resistance as therapy for severe mitral regurgitation of valvular origin. Annals of Internal Medicine, 83, 312-316.

Kelly, D. T., Delgado, C. E., Taylor, D. R., Pitt, V., and Ross, R. S. (1973). Use of phentolamine in acute myocardial infarction associated with hypertension and left ventricular failure. Circulation, 47, 729-735.

Kerber, R. E., and Abboud, F. M. (1975). Effect of alterations of arterial blood pressure and heart rate on segmental dyskinesis during acute myocardial ischemia and following coronary reperfusion. Circulation Research, 36, 145-155.

Kerber, R. E., Marcus, M. L., Ehrardt, J., and Abboud, F. M. (1976). Effect of intra aortic balloon counterpulsation on the motion and perfusion of acutely ischemic myocardium. An experimental echocardiographic study. Circulation, 53, 853-859.

Killip, T., and Kimball, J. T. (1967). Treatment of myocardial infarction in a coronary care unit. American fournal of Cardiology, 20, 457-464.

Lang, T. W., Meerbaum, S., Corday, E., Hashimoto, K., Davidson, R., Osher, J., and Katz, J. (1976). Comparative regional effects of intravenous and sublingual administration of nitroglycerin during acute myocardial ischemia. American fournal of Cardiology, 37, 150.

Luebs, E. D., Cohen, A., Zaleski, E. J., and Bing, R. J. (1966). Effect of nitroglycerin, intensain, isoptin and papaverine on coronary blood flow in man. Measured by the coincidence counting technic and rubidium. American fournal of Cardiology, 17, 535-541.

Majid, P. A., Sharma, B., and Taylor, S. H. (1971). Phentolamine for vasodilator treatment of severe heart-failure. Lancet, 2, 719-724.

Mantle, J. A., Russell, R. O., Jr., Moraski, R. E., and Rackley, C. E. (1976). Isosorbide dinitrate for the relief of severe heart failure after myocardial infarction. American fournal of Cardiology, 37, 263-268.

Mikulic, E., Franciosa, J. A., and Cohn, J. N. (1975). Comparative haemodynamic effects of chewable isosobide dinitrate and nitroglycerin in patients with congestive heart failure. Circulation, 52, 477-482.

Miller, R. R., Vismara, L. A., Zelis, R., Amsterdam, E. A., and Mason, D. T. (1975). Clinical use of sodium nitroprusside in chronic ischemic heart disease. Circulation, $\mathbf{5 1}$ 328.

Milnor, W. R. (1975). Arterial impedance as ventricular afterload. Circulation Research, 36, 565-570.

Mueller, H., Religa, A., Evans, R., and Ayres, S. (1974). Metabolic changes in ischemic myocardium by nitroprusside. American fournal of Cardiology, 33, 158.

Pepine, C. J., Nichols, W. W., Curry, R. C., and Conti, C. R. (1976). Reversal of premature mitral valve closure by nitroprusside infusion in severe aortic insufficiency: beat to beat pressure-flow and echocardiographic relationships. American fournal of Cardiology, 37, 161.

Perret, Cl., Gardaz, J. P., Reynaert, M., Gimbert, F., and Enrico, J. F. (1975). Phentolamine for vasodilator therapy in left ventricular failure complicating acute myocardial infarction. Haemodynamic study. British Heart fournal, 37, 640-646.

Ramanathan, B. K., Raina, S., Bodenheimer, M. M., Banka,
V. S., and Helfant, R. H. (1975). The contrasting effects of nitroprusside and phentolamine on local contraction and degree of ischemia after coronary occlusion. Clinical Research, 23, 569.

Ratshin, R. A., Rackley, C. E., and Russell, R. O., Jr. (1972). Hemodynamic evaluation of left ventricular function in shock complicating myocardial infarction. Circulation, 45, 127-139.

Rowe, G. G., and Henderson, R. H. (1974). Systemic and coronary hemodynamic effects of sodium nitroprusside. American Heart fournal, 87, 83-87.

Scheidt, S., Wilner, G., Fillmore, S., Shapiro, M., and Killip, T. (1973). Objective haemodynamic assessment after acute myocardial infarction. British Heart fournal, 35, 908-916.

Shell, W. E., and Sobel, B. E. (1974). Protection of jeopardized ischemic myocardium by reduction of ventricular afterload. New England fournal of Medicine, 291, 481-486.

Singh, J. B., Hood, W. B., and Abelmann, W. H. (1970). Beta-adrenergic-mediated inotropic and chronotropic actions of phentolamine. American fournal of Cardiology, 26, 660 .

Sniderman, A. D., Marpole, D. G. F., Palmer, W. H., and Fallen, E. L. (1974). Response of the left ventricle to nitroglycerin in patients with and without mitral regurgitation. British Heart fournal, 36, 357-361.

Sonnenblick, E. H. (1962). Force-velocity relations in mammalian heart muscle. American fournal of Physiology, 202, 931-939.

Swan, H. J. C., Forrester, J. S., Danzig, R., and Allen, H. N. (1970). Power failure in acute myocardial infarction. Progress in Cardiovascular Disease, 12, 568-600.

Taylor, W. R., Forrester, J. S., Magnusson, P., Takano, T., Chatterjee, K., and Swan, H. J. C. (1975). The hemodynamic effects of nitroglycerin ointment in congestive heart failure. Circulation, 51 and 52, Suppl. II, 36.

Walinsky, P., Chatterjee, K., Forrester, J., Parmley, W. W., and Swan, H. J. C. (1974). Enhanced left ventricular performance with phentolamine in acute myocardial infarction. American fournal of Cardiology, 33, 37-41.

Weber, K. T., Ratshin, R. A., Janicki, J. S., Rackley, C. E., and Russell, R. O. (1973). Left ventricular dysfunction following acute myocardial infarction. A clinicopathologic and haemodynamic profile of shock and failure. American fournal of Medicine, 54, 697-705.

Williams, D. O., Amsterdam, E. A., and Mason, D. T. (1975a). Hemodynamic effects of nitroglycerin in acute myocardial infarction. Decrease in ventricular preload at the expense of cardiac output. Circulation, 51, 421-427.

Williams, D. O., Hilliard, G. K., Cantor, S. A., Miller, R. R., and Mason, D. T. (1975b). Comparison of nitroprusside and phentolamine in left ventricular impedance reduction therapy of cardiac failure. Clinical Research, 23, 88.

Wolk, M. J., Scheidt, S., and Killip, T. (1972). Heart failure complicating acute myocardial infarction. Circulation, 45, $1125-1138$.

Zahir, M., and Gould, L. (1971). Phentolamine and beta adrenergic receptors. Fournal of Clinical Pharmacology, 11, 197-203.

Requests for reprints to Dr. Kanu Chatterjee, Room 1186 Moffitt Hospital, University of California, San Francisco, California 94143, U.S.A. 